\title{
Future Neuroradiology
}

\author{
Claus Zimmer ${ }^{1}$. Johannes Trenkler ${ }^{2}$
}

Published online: 5 June 2019

(c) Springer-Verlag GmbH Germany, part of Springer Nature 2019

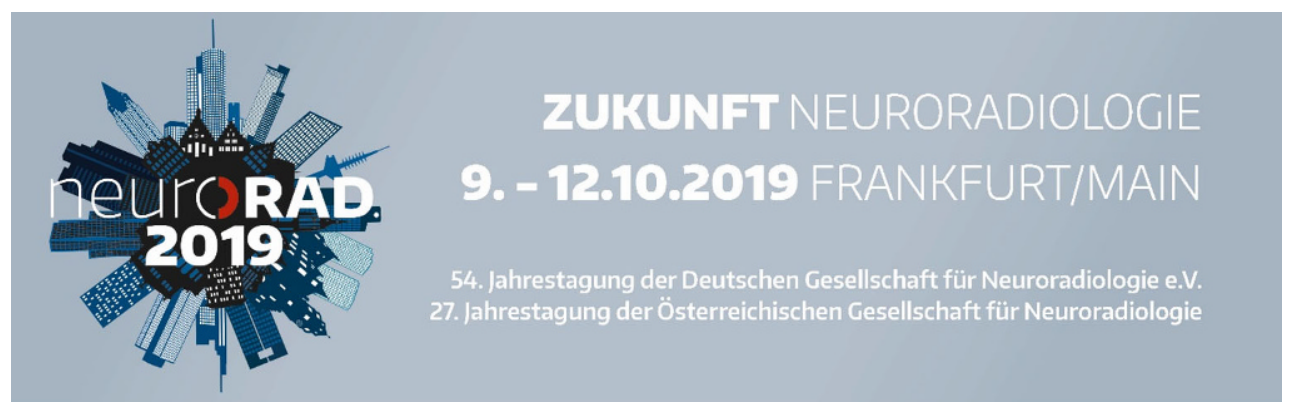

Dear Colleagues,

after the very successful start in 2018, we would like to invite you once again to the 54th Annual Meeting of our Society in Kap Europa in Frankfurt am Main.

The motto of this year's congress is "Future Neuroradiology". We will emphasize the importance of neuroradiology as a cross-sectional subject for the medicine of the future and address the question which changes in diagnostics and treatment can be expected from new developments related to artificial intelligence.

For the first time this year, we will therefore be launching the StAR Lounge (Start-up and Applied Research), a forum which aims at bringing together innovators and potential users of new solutions in order to inspire discussions about advancements in the field. Additionally, we will offer a one-day pre-congress workshop on "Artificial Intelligence for Neuroradiologists" on Wednesday.

We will take into account the interdisciplinary nature of neuroradiology by discussing the major disease-related topics of neuro-oncology, inflammatory CNS disorders, neurodegeneration, spinal and cerebrovascular diseases together with renowned colleagues from neighboring disciplines.

In order to offer attractive presentation opportunities to the next generation of physicians and scientists, the congress participants can expect another innovation in 2019. The best abstracts will be presented as "Power Pitches", where the speakers face the challenge of making their project appealing to a large audience in a very short period of time before the topic is subsequently discussed in depth at the poster places.

In addition to these innovations, we are of course continuing well-proven topics from the last years: "Fit für den Facharzt", the continuing medical education academy, the video cases on interventional neuroradiology and distinct lectures for technicians and radiographers are established components of the annual meeting just like the keynote lectures and the neuroanatomy course that started last year.

Claus Zimmer

claus.zimmer@tum.de

1 Abteilung für Neuroradiologie, Klinikum rechts der Isar, TU München, München, Germany

2 Institut für Neuroradiologie, Kepler Universitätsklinikum, Linz, Austria 
Moreover, following the success of the past year, we will also be offering the German Stroke School for our foreign and German-speaking specialist colleagues. Following a good tradition, we are again organizing the annual meeting 2019 together with the Austrian Society of Neuroradiology (ÖGNR) and we hope for many participants from our neighboring country.

We look forward to seeing you in Frankfurt in October!

Yours sincerely,

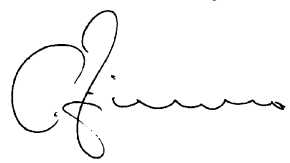

Prof. Dr. Claus Zimmer, Munich

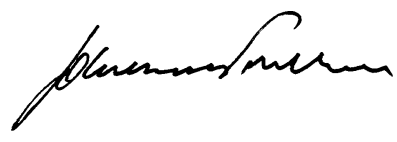

Prim. Dr. Johannes Trenkler, Linz

Presidents of the 54th Annual Meeting of the German Society of Neuroradiology and the 27th Annual Meeting of the Austrian Society of Neuroradiology, 9-12 October 2019 Frankfurt am Main.

Conflict of interest C. Zimmer and J. Trenkler declare that they have no competing interests. 